\title{
An Evolutionary Sceptical Challenge to Scientific Realism
}

\author{
Christophe de $\operatorname{Ray}^{1}{ }^{\text {(D) }}$
}

Received: 21 May 2019 / Accepted: 3 February 2020 / Published online: 9 March 2020

(c) The Author(s) 2020

\begin{abstract}
Evolutionary scepticism holds that the evolutionary account of the origins of the human cognitive apparatus has sceptical implications for at least some of our beliefs. A common target of evolutionary scepticism is moral realism. Scientific realism, on the other hand, is much less frequently targeted, though the idea that evolutionary theory should make us distrustful of science is by no means absent from the literature. This line of thought has received unduly little attention. I propose to remedy this by advancing what I will call an evolutionary sceptical challenge to scientific realism. I argue that, given standard evolutionary theory, our possession of sound innate metaphysical intuitions would have taken an epistemically problematic 'lucky accident'. This, as I will show, entails that scientific realism is a selfundermining position. I discuss objections to my argument's two premises, including ones that appeal to the success of the sciences and to the possibility that sound innate metaphysical intuitions evolved as an evolutionary 'by-product'. I then draw out an advantage of my argument over a similar one recently put forward by Graber and Golemon (Sophia, 2019. https://doi.org/10.1007/s11841-018-0695-0). I finish by submitting that scientific realism, given the soundness of my argument, is faced with a new 'Darwinian Dilemma', and briefly address the significance of this for the debate between realists and anti-realists in the philosophy of science.
\end{abstract}

\section{Introduction: Evolutionary Scepticism}

Ever since its inception, evolutionary theory has been thought to have worrying epistemological implications. Darwin himself famously voiced the worry as follows:

"With me the horrid doubt always arises whether the convictions of man's mind, which has been developed from the mind of the lower animals, are of any value or at all trustworthy. Would any one trust in the convictions of a monkey's mind, if there are any convictions in such a mind?" (Darwin and Darwin 1888)

Christophe de Ray

christophe.de_ray@kcl.ac.uk

1 King's College London, 30A Butler Road, Harrow, Middlesex HA1 4DR, UK 
The thought here is that the evolutionary origins of human minds ought to make us distrustful of such minds. Such evolutionary scepticism has been taken up in more recent times, not least in metaethical contexts. Sharon Street's notorious 'Darwinian Dilemma for realist theories of value' (2006) argues that given moral realism and barring empirically implausible views of evolution, it would have taken an epistemically problematic "happy coincidence" for the evolutionary process to have given us cognitive capacities to form mostly true moral beliefs. Her argument and various others have spawned a sizeable literature on so-called 'evolutionary debunking arguments against morality'. ${ }^{1}$

While moral realism is a frequent target of evolutionary scepticism, scientific realism is much less commonly targeted. It is not difficult to see why: as Thomas Nagel notes, there is something "strange, to the point of incoherence" about the thought that evolutionary theory, a paradigm scientific theory, is grounds for "antirealism about natural science" (2012, p. 75).

Even so, the idea of an evolutionary sceptical challenge to scientific realism is by no means unheard of in contemporary analytic philosophy. Clark (1984), Ruse (1995, 1998) and, in more recent times, Talbott (2016), Severini and Sterpetti (2017), Koperski (2017) have put forward or at least gestured towards arguments of this sort. ${ }^{2}$ The arguments differ in the details, but share a common main thrust: standard evolutionary theory implies that it would have taken an epistemically problematic 'lucky accident' for the evolutionary process to have given us a cognitive apparatus with the capacity to acquire a scientific understanding of the world.

It is my view that this line of argument has received unduly little attention. I hope to remedy this by putting forward one such argument myself. I begin by arguing in Sect. 2 that scientific realists are committed to at least one metaphysical belief, namely, the belief that facts generally have explanations for their obtaining. This belief, I claim, is most plausibly a product of innate metaphysical intuition. In Sect. 3. I present my main argument and motivate its premises. I will argue that given standard evolutionary theory, our possession of sound innate metaphysical intuitions would have taken an epistemically problematic 'lucky accident'. This, as I will show, entails that scientific realism is a self-undermining position, since it entails that scientific realists ought to withhold the belief that facts generally have explanations for their obtaining. I address objections in Sects. 4 and 5, and discuss an advantage of my argument relative to the most recent evolutionary sceptical challenge to science in the literature, i.e. the one advanced by Graber and Golemon (2019), in Sect. 6. I finish by submitting that scientific realism, given the soundness of my argument, is faced with a new 'Darwinian Dilemma', and briefly address the

\footnotetext{
1 cf. Bogardus (2016) for a useful overview.

2 I do not have the space to discuss in detail the other, less recent arguments mentioned above with reference to my argument. I will only say that the arguments of Koperski (2017) and Severini and Sterpetti (2017) are largely tentative and promissory, and that those in Clark (1984) and Ruse $(1995,1998)$ rely on epistemological principles subtly different to the one my argument will rely on. Cf. Lemos (2002) for a discussion of Ruse's evolutionary scepticism. Talbott's argument (2016) will be discussed in Sect. 4.2 of this paper.
} 
significance of this for the debate between realists and anti-realists in the philosophy of science.

\section{Scientific Realism and Explanation}

I take 'scientific realism' to be the view that our best scientific theories accurately represent real, mind-independent states of affairs. ${ }^{3}$

It is widely agreed that the methodology employed by the natural sciences is primarily abductive - that is, that inference to the best explanation (IBE) is its most central mode of inference. Peter Lipton (2003, pp. 56-64) characterizes IBE as a two-stage process:

1. Generation scientists imagine different potential explanations for the evidence at hand, and, in doing so, generate a set of 'candidate' scientific theories.

2. Selection scientists consider the set of candidate theories and rank them according to how well they explain the evidence. The best explanation is then inferred to be the actual explanation of the evidence.

An explanation is 'good', or in Lipton's terms 'lovely' to the extent that it exemplifies the so-called theoretical virtues-simplicity, coherence, fit with evidence and background knowledge, predictive power, and so on. ${ }^{4}$ Once identified, the best explanation is inferred to be true explanation of that which we are trying to explain. In other words, the final step of an abductive inference is a move from ' $T$ would best explain $E$ ' to ' $T$ actually explains $E$ ' (where ' $T$ ' is some theory and ' $E$ ' is some explanandum).

Such a move is not self-evidently legitimate: for any given explanandum, it is in general possible to conceive of it as lacking an explanans. More generally, it seems perfectly possible to conceive of a world that contains a vast number of arbitrary brute facts at every ontological level. It is clear that abductive reasoning as described above would not be a reliable guide to scientific truth in such a world. Indeed, it would not in general be the case that the best explanation of some piece of evidence is also the actual explanation of said evidence. In particular, the inference from the explanatory virtue of a theory to its truth would not result in many true scientific theories.

It would appear, then, that engaging in abductive reasoning requires one to presuppose that the world has a certain character-namely, that it is explainable, i.e. such that those states of affairs which admit of good potential (or candidate) explanations also have actual explanations. This is different to saying that all facts have explanations: some facts may be such that their nature makes it metaphysically impossible for them to be explained, e.g. if they belong to some special class of

\footnotetext{
${ }^{3}$ Cf. Anjan Chakravartty's characterisation of scientific realism as the view that our best scientific theories "correctly describe the nature of a mind-independent world" (2007, p. 4)

${ }^{4}$ Cf. Keas (2017) for a recent taxonomy. I shall have more to say about theoretical virtues in Sect. 6.
} 
fundamental facts, or if they involve the outcome of some intrinsically chancy process. ${ }^{5}$ Hence I will gloss the presupposition as the belief that facts generally have explanations for their obtaining.

If, as I will assume, it is correct to say that scientific theories are (at least in general) products of abductive reasoning, and that reasoning abductively requires one to believe that the world is 'explainable' in the above sense, it follows that scientific realists, by virtue of being such, must hold this belief.

Insofar as this belief is about the character of the world 'as a whole' rather than about some of its parts, it seems appropriate to call it, following Chang (2008), a metaphysical belief. ${ }^{6}$ The picture that emerges from this basic metaphysical commitment is one of a world exhibiting a deep explanatory structure, such that, for instance, the observable 'surface' features of everyday objects like colour and texture are explained by unobservable 'deep' properties or natures, such as molecular structure. As such, the realist is committed to rejecting the empiricist slogan that "in science, there are no 'depths', there is surface everywhere" (Carnap, Neurath and Hahn 1929, quoted in Peter Godfrey-Smith 2003).

The belief that facts generally have explanations for their obtaining enjoys considerable support from intuition. When faced with a novel fact, we intuitively feel that there must be some reason for its obtaining - to use an old example, the thought that nothing explains the disappearance of my cheese and the appearance of little dark pellets on the floor this morning strikes us as absurd.

There is good empirical reason to regard the intuition that the world is explainable in the relevant sense as having a strong biological basis and thus as being innate (or 'in-built'), as I will argue in Sect. 3.3.2. The next section will present and motivate an argument to the effect that scientific realists, by virtue of being such, ought to distrust innate metaphysical intuition, and thus to withhold the metaphysical beliefs formed through it, such as the belief that facts generally have explanations for their obtaining.

\section{The Evolutionary Sceptical Challenge to Scientific Realism}

\subsection{The Argument}

I will take an intuition to be a kind of disposition to hold certain beliefs (following van Inwagen 1997). Thus, I will take it that an intuition is sound if the beliefs it produces are true. Moreover, I will take intuitions to be metaphysical if the content of the beliefs they produce is metaphysical.

\footnotetext{
${ }^{5}$ Hence I am not claiming that using IBE commits one to anything as strong as the rationalist 'Principle of Sufficient Reason'.

${ }^{6}$ I am aware that any non-trivial characterisation of the nature and scope of metaphysics is bound to be controversial. Even so, I will take it for granted that metaphysical beliefs at least tend to be about the overall or fundamental nature or structure of reality (cf. Fine 2001). As such, the belief that facts generally have explanations for their obtaining will be taken to count as a metaphysical belief.
} 
My argument is as follows:

(1) If, given evolutionary theory, the soundness of our innate metaphysical intuitions would not at all explain our reliance on said intuitions, then believing evolutionary theory ought to make us distrust our innate metaphysical intuitions.

(2) Given evolutionary theory, the soundness of our innate metaphysical intuitions would not at all explain our reliance on said intuitions.

(3) Therefore, believing evolutionary theory ought to make us distrust our innate metaphysical intuitions.

I take it that (3) follows straightforwardly from (1) and (2). I will thus motivate (1) and (2) in turn.

\subsection{Motivating (1)}

Forming beliefs requires us to rely on a multiplicity of belief-forming mechanisms and methods-perception, intuition, reliance on the testimony of some authority figure, and so on. Reliance on a belief-forming method may or may not be justified. For example, if my belief-forming method $\mathrm{M}$ has a consistent track record of leading me to form false beliefs (and I am aware of this fact), my continued reliance on $\mathrm{M}$ is clearly unjustified.

But there are more indirect ways for reliance on a belief-forming method to become unjustified. Suppose that my beliefs about the origins of my belief-forming method $\mathrm{M}$ implied that my use of or reliance on $\mathrm{M}$ is not in any way explained by the reliability of $\mathrm{M}$. Consider, for example, the case of drawing one's religious beliefs from some religious scripture. Suppose that, after doing some research on the origins of said scripture, I discover that its existence and acceptance in my religious community are the result of complex social and historical processes. Crucially, I find out that the reliability of the scripture in theological matters, if it obtains, played no part in such processes. In other words, I learn that my co-religionists and I do not rely on the scripture because forming beliefs in this way is a reliable belief-forming method. If the scripture is in fact a reliable source of theological beliefs, it is only so 'by accident'. It seems clear enough that if I acquire these beliefs about the mechanisms by which I acquired my theological beliefs, my continued reliance on said mechanisms would be unjustified.

This example illustrates a principle to the effect that awareness of a lack of appropriate explanatory connection between one's reliance on a belief-forming method $\mathrm{M}$ and the reliability of $\mathbf{M}$ makes continued reliance on $\mathbf{M}$ unjustified. Naturally, and as should be clear from the example, this sort of principle plays an important role in some epistemological challenges to religious belief. John Stuart Mill's comment that "the same causes which make [one] a churchman in London would have made him a Buddhist or a Confucian in Peking" (quoted in Baker-Hytch 2014) exemplifies this well: the thought is that the "causes" of a believer's reliance on a particular religious tradition have nothing to do with the trustworthiness of said tradition, since they 
belong to the same kinds of causes that lead to reliance on religious traditions that, from the believer's perspective, are not trustworthy.

In the example, there is a sense in which my reliance on a reliable belief-forming method would have taken a 'lucky accident'. Hence I will call the epistemological principle at work in the example LUCKY ACCIDENT (LA) and define it as follows:

LUCKY ACCIDENT (LA): if you believe that the origins of the belief-forming method $\mathrm{M}$ on which you rely for some of your beliefs are such that the reliability of $\mathrm{M}$ would not at all explain your reliance on $\mathrm{M}$, your continued reliance on $\mathrm{M}$ is unjustified. ${ }^{7}$

Now, take $M$ to be innate metaphysical intuition. Suppose (as I will argue in Sect. 2) that given evolutionary theory, the soundness of innate metaphysical intuitions would not at all explain our possession of such intuitions. It follows, given LA, that those who believe in evolutionary theory ought to distrust (i.e. refrain from relying on) innate metaphysical intuition

- thus my argument's first premise.

\subsection{Motivating (2)}

\subsubsection{Evolution and the human cognitive apparatus}

The term 'evolution' usually refers to change in the genotypic frequencies of a population (Sober 2000, p. $1^{8}$ ). An organism's genotype is the specific combination of genes that it has. Evolution occurs when the frequency of a certain genotype in a population increases or decreases. Such changes may underpin changes in the observable characteristics of individuals in the population (i.e. phenotypical changes).

Evolutionary theory concerns the causes of evolution. Such causes are aptly summed up by Donald Campbell's phrase: "blind variation and selective retention" (1960). Evolution, on standard evolutionary theory, is driven by both random and selective processes. First, genotypic variation is generated by genetic mutations, i.e. changes to the DNA sequence leading to the emergence of new genotypes. Secondly, some genotypes are retained and spread in the population because organisms that have them are more reproductively successful as a result of having them, while others diminish in frequency and may eventually be eliminated, since organisms that have them reproduce less than those with the more advantageous genes.

The retention and spread of genotypes is not only the result of natural selection: genotypes may also be retained and spread by chance, if for instance the organisms that have them just happen to be more reproductively successful then those who do not, even if having the genotype confers no advantage whatsoever (this is what evolutionary biologists call 'genetic drift').

It is these processes-mutation, selection, and drift—-that, according to the evolutionary account, brought about the human cognitive apparatus, i.e. the biological,

\footnotetext{
${ }^{7}$ See Locke (2014) and Isserow (2018) for similar principles.

${ }^{8}$ Elliott Sober (ibid. pp. 1-2) notes that this definition leaves out some less notable cases of evolution, but it will suffice for our purposes.
} 
belief-making mechanisms we use to navigate the world. It is accepted that selection played an important role in its evolution. The human brain is a very costly trait, using some $20 \%$ of the human body's total energy consumption. It therefore must have conferred some advantage to our prehistoric ancestors, otherwise it would have been eliminated by natural selection due to being unnecessarily costly. An explanation as to why the evolutionary process produced our cognitive machinery, then, will have to include the fact that such machinery was useful to our ancestors' survival and reproduction.

But how is this usefulness to be explained? Patricia Churchland provides us with a helpful summary:

"Boiled down to essentials, a nervous system enables the organism to succeed in the four F's: feeding, fleeing, fighting and reproducing. The principle chore of nervous systems is to get the body parts where they should be in order that the organism may survive" (1987).

Plausibly, at least part of what explains why our cognitive systems can perform these functions is that they form accurate beliefs about our immediate environments. The ability to accurately represent their environments would surely have helped our ancestors to, say, find food and avoid dangerous predators, thereby increasing their chances of surviving and reproducing. Beliefs, as Fred Dretske put it, "have the function and content of indicating the content and the nature of one's surroundings" (1988, p. 79). Similarly, evolutionary biologist Robert Trivers states that our sensory systems "evolved to give us a marvellously detailed and accurate view of the outside world" (2011). Notice the teleological wording of Trivers' phrase: the systems 'evolved to', i.e. in order to enable us to acquire accurate representations of the outside world. That is, the evolutionary process gave us such systems because they enabled us (or our ancestors) to acquire such representations.

It would appear, then, that on standard evolutionary theory, our reliance on our in-built cognitive and perceptual dispositions as ways of acquiring beliefs about our surroundings is partly explained by the reliability of said dispositions with respect to such beliefs.

\subsubsection{Evolution and Innate Metaphysical Intuition}

But this conclusion is too hasty. Not all kinds of true beliefs would have benefited our ancestors, in evolutionary terms. What the above considerations show is that dispositions to acquire a relatively superficial understanding of the objects they interacted with would have been beneficial. But it would not follow that the same is true of dispositions to acquire an understanding of the world so in-depth as to deserve to be called 'metaphysical'.

Consider our intuition that facts generally have explanations for their obtaining. There is good empirical reason to believe that it is the result of some of the in-built cognitive mechanisms given to us by the evolutionary process. Helen De Cruz and De Smedt $(2006,2017)$ refer to various pieces of research suggesting that infants and young children expect events to have causal explanations, positing invisible forces to explain the motion of inanimate objects, and underlying 
essences to explain the observable features and behaviour of animals and plants. The authors (2006) take this to show that the relevant intuitions about explanations and causality form part of our intuitive ontologies (or 'evolved metaphysics'), i.e. the metaphysical world-views that our evolved cognitive systems predispose us to believe (cf. Boyer 2000).

Granted, then, that our intuitive expectation that facts ought to have explanations is the result of innate cognitive mechanisms given to us by evolution, could evolution have selectively retained such mechanisms because they produced accurate metaphysical beliefs? Supposing that the world was indeed such that the facts that obtain in it generally have explanations for their obtaining, would there be any significant evolutionary benefit in being intuitively disposed to believing as much?

Perhaps, it could be argued, a failure to understand that the world has a deep explanatory structure would have resulted in unsuccessful behaviour. Stewart-Williams (2004) suggests that a hominid who disbelieved that his experiences of animals were causally explained by real, mind-independent animals would "stop pursuing its prey the instant it slipped from view" and fail to keep running from the tiger when they no longer see or hear it chase after him. Such behaviour is clearly not fitness-conducive. More generally, it looks as though knowing that facts generally have explanations would have enabled our ancestors to better predict and manipulate their environments, which is surely an advantage. Thus, we would be told, the innate metaphysical intuition that facts generally have explanations for their obtaining would have been useful, by virtue of being sound.

I submit that this is mistaken. For one thing, high reproductively successful behaviour seems perfectly consistent with being an intuitive empiricist of a Humean sort, disposed to believe that observable events follow stable, predictable patterns (e.g. 'the sun rises every morning') without there being any underlying causal or metaphysical explanations for why this is the case. The history of philosophy contains no shortage of enthusiastic advocates of this kind of empiricism-presumably, this did not stop them from living reproductively successful lives. Had our prehistoric ancestors been intuitive empiricists, they could still have behaved in fitnessconducive ways. Indeed, whether they represented tigers as groundless 'bundles of sensations' or mind-independent material beings underlying said sensations would not have mattered, as long as they stayed away from them. Getting mauled by a tiger is painful, even if the process is nothing over and above a series of unpleasant sensations. And even if they believed that tigers cease to exist when unexperienced, they could still have been wary of them while not experiencing them, as long as they also believed that sensations (and bundles of sensations, like tigers) are governed by sufficiently stable regularities. For instance, $\mathrm{Og}$ the empiricist caveman will continue to run from the tiger even when he no longer perceives it, because he knows that, if one has just experienced tiger-sensations and now isn't, one is very likely to experience them again shortly, unless one runs away. Alternatively, Og, despite firmly believing that experiences lack underlying mind-independent explanations, occasionally represents his experiences as having such explanations, knowing that this is just a useful heuristic, in much the same way that one might represent plants and insects as having beliefs and desires in order to predict their behaviour (e.g. 'the ant attacks the spider because he wants to protect the nest'). 
For another, insofar as the relevant intuition is about the character of the world 'as a whole', it is difficult to see how its soundness could be relevant to the reproductive success of prehistoric hominids. How would it have benefited our ancestors to know that events occurring at microscopic ontological levels, or in other galaxies, generally have explanations-even if it would have benefited them to know that the events involving the objects of their immediate environments did? It is often pointed out that many of our in-built metaphysical intuitions, while broadly accurate when restricted to everyday 'ordinary dry goods', break down when applied to other domains, such as the domain of fundamental physics. Evolutionary theory provides an elegant explanation for this: our belief-forming dispositions need only be reliable with respect to the objects of the human Umwelt in order to promote adaptive behaviour, if they need to be reliable at all. Accordingly, our in-built intuitions about the world's explanatory structure need only be sound with respect to some (relatively 'ordinary') facts in order to be beneficial, if they need to be sound at all.

Therefore, the soundness of the innate metaphysical intuition that facts generally have explanations for their obtaining would not make possessing said intuition a significant evolutionary advantage. This example apparently illustrates the general truth that high reproductive fitness is perfectly compatible with having unsound innate metaphysical intuitions, be they about the nature of objects, properties, causation, laws of nature and so on, for the simple reason that high reproductive fitness is perfectly compatible with lacking an accurate metaphysical world-view. ${ }^{9}$

But if so, there could have been no selection for the trait of having sound innate metaphysical intuitions, i.e. the innate metaphysical intuitions we actually have could not have been selectively retained by virtue of being sound. It appears, then, that on the evolutionary account of our origins, the soundness of our innate metaphysical intuitions would not at all explain our reliance on said intuitions. In other words, the required explanatory connection between reliance on and reliability of a belief-forming method, described in Sect. 3.2, does not hold, and premise (2) of my argument is true.

\subsection{Implication of (3): scientific realism in danger of undermining itself}

My argument's conclusion (3) states that 'believing evolutionary theory ought to make us distrust our innate metaphysical intuitions'. This conclusion is of course not a straightforward denial of scientific realism. Nonetheless, I will argue, it entails that scientific realism suffers from an interesting kind of incoherence.

\footnotetext{
9 Perhaps some innate metaphysical intuitions are such that their soundness would make it significantly beneficial (in evolutionary terms) to have them. Even so, the innate metaphysical intuition that facts generally have explanations for their obtaining would not belong in that category. Strictly speaking, this is all my argument would need to get off the ground, as will become evident in Sect. 3.4. I would only have to change the argument's conclusion (3) to 'Therefore, believing evolutionary theory ought to make us distrust the innate metaphysical intuition that facts generally have explanations for their obtaining'. If my reasoning in Sect. 3.4 is correct, this would be sufficient to generate a sceptical challenge for scientific realism.
} 
Recall, 'scientific realism' here refers to the view that our best scientific theories accurately represent mind-independent states of affairs. Now, insofar as evolutionary theory figures among our best scientific theories (which it surely does), it follows that scientific realists are compelled, by virtue of being scientific realists, to believe in evolutionary theory. But if (3) is true, this means that scientific realists, by virtue of being scientific realists, ought to distrust innate metaphysical intuitions-including, crucially, the innate metaphysical intuition that facts generally have explanations for their obtaining.

Insofar as the scientific realist's belief that facts generally have explanations is the result of the latter intuition, ${ }^{10}$ distrusting innate metaphysical intuition requires scientific realists to withhold this belief. But we have seen in Sect. 2 that scientific realists are committed to the belief that facts generally have explanations for their obtaining. Withholding this belief, then, would amount to withholding belief in scientific realism. Therefore, the truth of (3) would entail that scientific realists, by virtue of being scientific realists, ought to withhold belief in scientific realism: in other words, scientific realism undermines itself. ${ }^{11}$

I take it that this explains the appearance of "incoherence" noted by Nagel (quoted in Sect. 1) in the idea of an evolutionary sceptical challenge to scientific realism. The evolutionary sceptical challenge is not itself incoherent, but rather aims to show that scientific realism is incoherent, due to being self-undermining.

I will now address objections to my argument. The first two will be objections to premise (1). The third will be an objection to the effect that, even granted the truth of the argument's conclusion (3), it does not follow that scientific realism undermines itself, because scientific realists need not rely on innate metaphysical intuition for their belief that facts generally have explanations for their obtaining.

\section{Objections to (1)}

Recall, the 'LUCKY ACCIDENT' principle (LA) states that if one believes that the required explanatory connection between the reliability of one's belief-forming method $\mathrm{M}$ and one's reliance on $\mathrm{M}$ does not hold, one's continued reliance on $\mathrm{M}$ is unjustified (cf. 2.2.). Since (1) is merely a direct application of LA, objections to (1) will have to target LA. I address two such objections in this section.

\subsection{The Ubiquity of Luck}

A natural way of attacking LA emphasizes that epistemological 'lucky accidents' are ubiquitous and no cause for concern.

\footnotetext{
10 Section 5 will consider an objection to the effect that scientific realists do not hold this belief on the basis of any in-built intuition.

11 Evolutionary sceptical arguments targeting metaphysical beliefs or intuitions have been advanced in various places (e.g. Boulter 2007; Ladyman and Ross 2007; McNabb 2015). To my knowledge, however, the implication that scientific realism undermines itself has not been explicitly drawn out.
} 
There is indeed nothing unusual about acquiring true beliefs, or relying on a reliable belief-forming method 'by accident'. As Bogardus (2016) notes in response to Sharon Street's 'Darwinian Dilemma' against moral realism, it may be just a matter of luck that I was born in epistemically favourable circumstances, e.g. in a country/ society where evidence is readily available, or where proper epistemic norms are taught. ${ }^{12}$ It is, for instance, a matter of luck that I rely on my reliable thermometer as a way of acquiring beliefs about the temperature: I could perhaps have been born at some place and time where reliable thermometers were unavailable. I was not born at the place and time where I was born because said place/time was one in which reliable thermometers were readily available-presumably, no one ensured that I would be born in a context where they were. The fact that the context in which I find myself is one where reliable thermometers are available is therefore a kind of 'lucky accident'. But surely believing as much does not entail that my continued reliance on thermometers is unjustified.

There is, however, an important difference between the above case and the 'religious scripture' case, which I mentioned in motivating LA (cf. Sect. 2). Recall, in the latter case, I discover that the reliability of the scripture in theological matters (if it obtained) would have played no explanatory role in the processes that led up to the scripture's existence and my reliance on it for my theological beliefs. It would therefore be incorrect for me to say that I rely on the scripture because it is reliable. In the thermometer case, in contrast, I do not acquire the belief that the reliability of my thermometer is explanatorily irrelevant to my reliance on it. For I believe that my thermometer was manufactured according to a reliable design, and distributed and thus made available to me because of that. Hence in this case, the reliability of my belief-forming method does play an explanatory role in the processes that led up to my reliance on it. This is so even if countless other factors were involved in the process - such as the fact that I was born in circumstances where the kind of thermometer to which mine belongs is available.

To sum up, the two cases are different in that, in the 'religious scripture' case, the reliability of the scripture would not at all explain the believer's reliance on it, whereas in the 'thermometer' case, the reliability of the thermometer contributes to the explanation of the user's reliance on it. This difference highlights the importance of the 'at all' clause in LA. The principle is meant to cover cases in which the reliability of the belief-forming method $\mathrm{M}$ does not even contribute to the explanation of one's reliance on M. While the thermometer case does arguably exemplify a kind of 'luck', it is not same as the luck involved in LA and therefore fails to constitute a counterexample to LA.

\subsection{Modally Robust Lucky States of Affairs}

Another way of objecting to LA would hold that, for one to justifiably rely on a belief-forming method $\mathrm{M}$, it is enough for one to believe the reliability of $\mathrm{M}$ to be

12 Cf. White (2010) and Mogensen (2016) for a similar argument. 
sufficiently modally robust. That is, it is enough for one to believe that there are no (or very few) nearby possible worlds in which $\mathrm{M}$ is not reliable.

Lackey (2008) has convincingly argued that a state of affairs can be both 'lucky' in the relevant sense and modally robust. To use her example, suppose that I bury a treasure at a certain location L, and you decide to plant a bush at L, thereby discovering my treasure. This would indeed be a lucky state of affairs, since there would be no causal connection between me burying my treasure at $\mathrm{L}$, and you planting your bush at L. Importantly, this is so even if, for whatever reason, there are no (or very few) nearby possible worlds in which I do not bury my treasure at L, and you do not plant your bush at L.

The scientific realist, then, might propose the following epistemological principle as a rival to LA:

MODALLY ROBUST (MR): if you believe that the origins of some beliefforming method $\mathrm{M}$ on which you rely for some of your beliefs are such that there are many nearby possible worlds in which $\mathrm{M}$ is not reliable, your continued reliance on $\mathrm{M}$ is unjustified.

Strictly speaking, MR and LA could both be true. But the realist may nevertheless argue that MR better captures the 'anti-luck' intuitions that supposedly motivated LA. He could hold that the sort of 'luck' described in LA is not really epistemically problematic. What is epistemically problematic, he could say, is when there are many nearby possible worlds in which my belief-forming method $\mathrm{M}$ is unreliable with respect to $\mathrm{B}$, which is of course the sort of situation described in MR. Thus, to return to the example in Sect. 3.2, the reason why I ought to withhold trust in the religious scripture is not that its reliability figures nowhere in the explanation of why I rely on it (contra LA), but rather that there are many nearby worlds in which it is unreliable (in accordance with MR).

Having rejected LA in favour of MR, all the realist needs to do is to show that there are in fact no (or very few) nearby possible worlds in which we have unsound in-built intuitions about the overall nature and/or structure of the world. He can do so by first arguing that there are no (or very few) nearby possible worlds in which the evolutionary process has not given us unsound innate metaphysical intuitions. Given evolutionary theory, there are arguably few nearby worlds in which the evolutionary process gives us a cognitive apparatus significantly different to the one which we actually possess, hence this first step should not prove too difficult. ${ }^{13}$ Hence, if the realist conjoins belief in the latter proposition with the belief that our innate metaphysical intuitions are in fact sound, he can claim that his reliance on such intuitions meets the condition of justification laid out by MR, LA notwithstanding.

This sort of response to evolutionary scepticism is exemplified by what may be called by-product solutions. These responses consist in arguing that we should expect reliable cognitive dispositions to evolve as likely 'by-products' of the

\footnotetext{
13 Similarly, Clarke-Doane (2016, p. 29) notes in response to some evolutionary sceptical challenges to morality that evolution could not easily have given us significantly different moral dispositions.
} 
evolutionary process, and that this is sufficient for reliance on said dispositions to be justified.

For example, Talbott (2016) proposes that the "challenge" put forward by evolutionary sceptics is to show how the "evolutionary process (...) could be expected to produce beings with any significant degree of positive reliability" (emphasis mine) with respect to domains beyond that of "ordinary, observable events", such as the domains of physics or geology. This is in line with seeing MR, or a principle like it, as underscoring the anti-luck intuitions motivating evolutionary scepticism: the problem is that evolutionary theory seems to imply that we could easily have failed to be relevantly reliable. The task is to show that this is not so.

Accordingly, Talbott points to the ability to be a "good learner"- that is, to form and withhold beliefs according to universal standards of epistemic rationality. This includes the capacity to reason abductively, conceiving of candidate explanations that fit the evidence and correctly identifying counter-evidence to one's beliefs, revising the latter accordingly. Such a capacity would have been conducive to reproductively successful behaviour, since being able to revise one's beliefs about, say, which kinds of predators are dangerous or which plants are edible allows one to adapt one's behaviour in variable environments. ${ }^{14}$ Hence this capacity would likely have been selectively retained. But, as it happens, being able to reason according to appropriate epistemic standards means that one will also be able to form true beliefs about parts or features of the world that are irrelevant to reproductive success. Thus the latter ability, while not itself selectively retained, is a likely by-product of a trait that was selectively retained.

Likewise, perhaps, the scientific realist could argue that having a sound in-built intuition about the explanatory structure of the world would have been a likely byproduct of selection for some other trait $\mathrm{T}$. If this is correct, then MR would not rule out reliance on innate metaphysical intuitions, since it would not be the case that there are many nearby worlds in which the evolutionary process gives us unsound in-built intuitions about the overall nature and/or structure of the world. Hence, the scientific realist who replaces LA with MR can avail himself of these 'by-product' strategies to neutralize evolutionary scepticism. ${ }^{15}$

But the realist cannot replace LA with MR, because the specific kind of 'luck' described by LA is epistemically problematic, regardless of modal (or probabilistic) considerations. Take once again the 'religious scripture' case: recall, I discover that the reliability of the scripture in theological matters played no part in the processes that led up to my reliance on the scripture for his theological beliefs. This, I argued, would make it unjustified for me to rely on the scripture as a source of theological beliefs. Suppose now that the scripture is in fact theologically reliable, i.e. that most of what it says about the divine is true - that there is a single, all-good, all-knowing,

\footnotetext{
${ }^{14}$ In their response to evolutionary scepticism, Vlerick and Broadbent (2015) argue that the environments in which our prehistoric ancestors evolved were markedly unstable, and thus such that more reflective doxastic practises would have been favoured by natural selection.

${ }^{15}$ By-product' (or 'third-factor') strategies are also used against evolutionary sceptical arguments to morality, cf. Enoch (2011, p. 159).
} 
all-powerful deity who rewards good and punishes evil (etc.). Suppose also that it was produced by a corrupt ruling class who wished to use it to control their subjects. There are few nearby possible worlds in which the corrupt ruling class produces a substantially different religious scripture, since (let us assume) they are not very imaginative and the religious narrative they created was the most effective one that they could think of. Suppose finally that I believe all of the latter. This is therefore a case in which I believe that, given the nature of the origins of my belief-source, there are not many nearby worlds in which my belief-forming method $\mathrm{M}$ is unreliable, and hence one in which MR does not bar me from relying on M. Notice, moreover, that the reliability of the scripture in this scenario is a likely by-product of (artificial) selection for usefulness. Even so, it is intuitively clear that my continued use of $\mathrm{M}$ would not be justified in this case. LA, unlike MR, explains why this is so: in the example, the explanation of the fact that I rely on $\mathrm{M}$ has nothing to do with the reliability of $\mathrm{M}$.

I conclude that while rejecting LA in favour of MR would be attractive to the realist since it would allow him to make use of 'by-product'-style responses to evolutionary scepticism, he cannot do so, because the luck involved in LA is epistemically problematic, independently of considerations of modal robustness.

\section{The Success of the Sciences: Should (3) Really Bother the Realist?}

I will now address an objection to the effect that, contrary to what has been argued in Sect. 3.4, my argument's conclusion (3)—which entails that scientific realists ought to distrust innate metaphysical intuition (insofar as scientific realists ought to believe evolutionary theory, as is surely the case) — does not imply that scientific realism is self- undermining, and therefore does not threaten scientific realism.

Some realist philosophers happily accept that an evolutionary etiology of our innate cognitive dispositions has sceptical implications for many of our metaphysical beliefs. For example, Ladyman and Ross (2007) present a case against a priori metaphysics motivated by evolutionary theory. "[Proficiency] at inferring (...) any features of parts of the universe distant from our ancestral stomping grounds was of no relevance to our ancestors' reproductive fitness" (p. 7), they tell us. Therefore, to rely on "armchair intuitions about the nature of the universe" amounts to "ignoring central implications of evolutionary theory (...) concerning the nature of our minds" (p. 10).

Evolutionary theory, then, ought to make us distrustful of the in-built metaphysical intuitions given to us by the evolutionary process, including, presumably, the intuition that facts generally have explanations for their obtaining - so far, the authors and I are in agreement. However, Ladyman and Ross go on to argue that our metaphysical beliefs can be immune to evolutionary scepticism if they are formed by scientific means, having been inferred by one or more of our best scientific theories, rather than formed a priori through our natural, unaided cognitive endowments. 
Paul Churchland's distinction between "native" and "artificial" belief-forming capacities may help to understand why this is so (2009). ${ }^{16}$ Beliefs about, say, the properties of electrons are the result of sophisticated instruments and institutions developed over the centuries by scientists. These effectively form an 'artificial' cognitive apparatus, which greatly improves on the far more limited 'native' cognitive apparatus given to us by biological evolution. Likewise, Ladyman and Ross contend that while we are "poorly prepared by evolution" to acquire true beliefs concerning matters irrelevant to our ancestors' survival (p. 7), the "institutional filters of science" are able to "[bootstrap] the process of scientific learning beyond the capacities of individual minds" (p. 300). This is what legitimates the particular kind of naturalized metaphysics they recommend, as oppose to the a priori metaphysics they deem discredited by evolutionary considerations.

The realist could avail himself of the foregoing suggestions in a response to my argument, as follows. Once again, my argument's conclusion entails that scientific realists ought to distrust innate metaphysical intuition. The realist could grant this, but nevertheless insist that he is entitled to retain the belief that facts generally have explanations for their obtaining. He can do so, it would be argued, because he does not in fact rely on innate metaphysical intuition, or any other 'native' belief-forming disposition, for this belief. Rather, he relies on the system 'artificial' belief-forming methods that is science, with its sophisticated institutions and instruments. After all, the 'picture' of the world given to us by the natural sciences is one of a deep explanatory structure. Perhaps, then, believing that facts generally have explanations for their obtaining is just a matter of trusting science as a guide to reality, not in-built metaphysical intuition. But in that case, it does not follow from (3) that scientific realists, by virtue of being realists, ought to withhold the belief that facts generally have explanations for their obtaining. And if so, nor does it follow that scientific realism undermines itself in the way that I explained in Sect. 3.4, in which case my argument will have failed to really challenge scientific realism at all.

Furthermore, the realist can argue that, in the case of science (rather than innate belief-forming mechanisms), the required explanatory connection between reliability of and reliance on a belief-forming method described in Sect. 3.2 does hold. He can argue as much by appealing to the impressive predictive success of our best scientific theories. Science, by producing incredibly successful theories, has shown itself to be a reliable means of acquiring true beliefs about the world, since its reliability is the best (and perhaps the only) explanation for such success. This, the realist could say, is why he relies on science. Hence, the reliability of science as a source of beliefs about the world contributes to the explanation of why the realist relies on it-his reliance on a reliable means of acquiring beliefs about the overall nature and structure of the world is no 'lucky accident' in the sense described by the LA principle. Ladyman and Ross argue along similar lines: the metaphysical beliefs of the realist (who subscribes to their preferred kind of naturalized metaphysics) are "vindicated by the success of science" (p.

\footnotetext{
16 Churchland puts forward this distinction in the context of a response to Alvin Plantinga's classic 'evolutionary argument against naturalism' (1993).
} 
7). A priori metaphysics, which relies on unaided human cognitive capacities, has achieved "nothing remotely comparable" (p. 16).

Unfortunately, the nature of the grounds for the realist's trust in science is such that this solution cannot succeed. Indeed, the realist claims not to rely on any inbuilt intuition for his belief that facts generally have explanations for their obtaining, but on science instead. And, when asked why he trusts science, he replies that science must be reliable, since otherwise we would have no good explanation for its impressive predictive success. This is of course an abductive inference, an inference to the best explanation. We saw in Sect. 2. that inferring beliefs in this way involved moving from the claim that some theory $\mathrm{T}$ is the best potential explanation of some evidence $\mathrm{E}$ to the claim that $\mathrm{T}$ actually explains $\mathrm{E}$. As I argued, making this move requires one to presuppose that our world is one in which the facts that obtain in it are at least not generally brute-otherwise, why infer that some unobservable entities exist from the fact that, if they did, they would explain some observed phenomenon?

But if this is correct, the realist, in order to infer the reliability of science from its predictive success, must believe that facts generally have explanations, prior to running the inference. If so, it cannot be the case that the realist believes that facts generally have explanations for their obtaining because he trusts science. Rather, the order of explanation is the opposite: he trusts science because he believes that facts generally have explanations, and thus that the predictive success of science must be explained by its reliability. Therefore, contrary to the objection, the scientific realist's belief that facts generally have explanations cannot be the result of relying on science.

Further, if this belief is not held as a result of trusting the a posteriori 'artificial' belief-forming methods of science, then it seems that it must be held as a result of some a priori 'native' belief-forming mechanism-and I can think of no more plausible candidate than innate metaphysical intuition. It follows that the scientific realist must rely on innate metaphysical intuition for his belief that facts generally have explanations for their obtaining, and thus that my argument's conclusion (3) does indeed threaten scientific realism.

I conclude that the scientific realist cannot deny the sceptical implications of my argument's conclusion by claiming to rely on science, and not in-built metaphysical intuition, for his belief that facts generally have explanations.

An interesting upshot of this is that a very popular consideration in favour of scientific realism, namely the impressive success of the sciences, is unable to defend scientific realism from evolutionary scepticism. The essence of the socalled 'No-Miracles' argument for scientific realism is well captured by Hilary Putnam's quip that "realism (...) is the only philosophy that doesn't make the success of science a miracle" (1975, p. 73). The thought is that such success would be utterly inexplicable if scientific realism was false. The argument is widely believed to be the strongest motivation for scientific realism. But, whatever its independent merits, we have just seen that appealing to the success of the sciences would not successfully deflect my evolutionary sceptical challenge. 


\section{Abraham Graber and Luke Golemon's Argument: A Comparison}

Graber and Golemon (2019) have advanced an argument that shares many features with mine. Their argument, like mine, targets scientific realism-more exactly in their case, scientific realism conjoined with metaphysical naturalism. They argue that, given a purely naturalistic etiology of our cognitive capacities, no explanatory connection holds between our preference for simplicity in theory selection on one hand, and the reliability of simplicity as a guide to scientific truth. But in that case, it would be "pure luck if our preference for simplicity happened to also serve as a veridical method of theory selection in the empirical sciences". This claim is motivated in a way that should be familiar by now: given standard evolutionary theory (and naturalism), the reliability of simplicity as a guide to scientific truth would form no part of the explanation as to why we rely on simplicity as a guide to scientific truth. Whether it is explained biologically or culturally, our preference for simplicity "significantly predates our first approximately true [scientific] theory", meaning that in either case, it is not true that we rely on simplicity as a guide to scientific truth because it is in fact reliable.

The authors take belief in this sort of 'luck' to be inconsistent with justifiably relying on this method as a means of theory selection. But, they argue, simplicity is crucial to theory selection in science. They conclude that believing in a purely naturalistic etiology of our cognitive capacities makes reliance on scientific methodology unjustified, which would of course undercut scientific realism.

The reader will have noticed the structural similarities of this argument with mine, particularly regarding the diagnosis of the evolutionary conundrum faced by the scientific realist-namely, that given standard evolutionary theory, the required explanatory connection between our reliance on a belief-forming method and the reliability of said method does not hold. The key difference is that Graber and Golemon's argument focuses specifically on simplicity as a guide to truth in science: the 'method' in question is using simplicity as a guide to scientific truth. Their argument is therefore committed to the view that simplicity is crucial to scientific methodology.

Such a view, while widely believed, is by no means universally held. It has been argued that appeals to a criterion of 'simplicity' by scientists in theory selection are really appeals to coherence with background beliefs (e.g. Sober 2015). Of all theoretical virtues purportedly used to select candidate theories, simplicity is arguably the most controversial, not least because there is much disagreement about its precise nature, e.g. between proponents of 'ontological' and 'syntactic' construals of simplicity.

Such controversy makes it reasonable to ask whether it is necessary for an evolutionary sceptical challenge to scientific realism to depend on any claim about how candidate explanations are evaluated and selected in science. Consider the following two claims:

(A) Scientific realists are committed to believing that facts generally have explanations for their obtaining. 
(B) Scientific realists are committed to believing that simpler explanations are more likely to be true.

(A) is surely much more modest and much less controversial than (B). Scientific realists may disagree about how to identify true explanations, but they must surely agree that there actually are explanations 'out there'. And if some belief about the features of real-world explanations (namely, that there are 'simple' in some sense) can be the target of evolutionary scepticism, there is no reason why the belief that such explanations exist could not likewise be targeted.

I submit, then, that my evolutionary sceptical challenge has the advantage of not depending on any assumption about the role of simplicity in science, or any other controversial assumption about what constitutes a good scientific explanation. I do not believe this advantage to come at any cost to the force of my argument.

\section{Conclusion: A New ‘Darwinian Dilemma’ for Scientific Realism}

I have put forward an evolutionary sceptical challenge to scientific realism and defended both of its premises. The core of my argument consists in the claim that, given standard evolutionary theory, it would have taken an epistemically problematic 'lucky accident' for the evolutionary process to have given us sound innate metaphysical intuitions. This is because, on standard evolutionary theory, the evolutionary process did not give us innate metaphysical intuitions because they are sound, if so they are. Hence, the soundness of our innate metaphysical intuitions would not at all explain our reliance on said intuitions [cf. premise (2)]. Awareness of this makes our continued trust in our innate metaphysical intuitions unjustified-or so I have argued [cf. premise (1)].

I argued in Sect. 3.4 that my argument's conclusion (3), which holds that believers in evolutionary theory ought to be distrustful of innate metaphysical intuition, entails that scientific realism undermines itself. In effect, scientific realists must be believers in evolutionary theory, since it figures among our most celebrated scientific theories. Furthermore, the scientific realist must hold at least one metaphysical belief - namely, the belief that facts generally have explanations for their obtaining-which he must hold on the basis of innate metaphysical intuition (indeed, I argued in Sect. 5 that he could not hold this belief on a posteriori scientific grounds). And once again, if being a scientific realist compels us to believe a theory such that, if we believe it, we ought to distrust our innate metaphysical intuitions, including those intuitions that one must rely on in order to believe scientific realism, then scientific realism is a self-undermining position.

I began this article by mentioning Sharon Street's 'Darwinian Dilemma' for moral realism. Accordingly, I will conclude this discussion with a 'Darwinian Dilemma' of my own, directed (unsurprisingly) at scientific realism. The choice is between believing in evolutionary theory or not. If the scientific realist rejects evolutionary theory, he cannot continue to be a scientific realist since he does not believe in the truth of at least one of our best theories. If on the other hand he believes evolutionary theory and my argument is sound, then he must as per (3) withhold the 
belief that facts generally have explanations for their obtaining, and thus withhold his belief in scientific realism. So, whichever horn he grasps, the scientific realist must reject scientific realism.

If my argument is sound, the scientific anti-realist has, as it were, a new arrow in his quiver. On top of arguing that inferences to the best explanation are unmotivated (cf. van Fraassen 1989), and that scientific methodology has a poor track-record of success (cf. Stanford 2006), he can now also argue that scientific realism undermines itself, being faced with an inescapable 'Darwinian Dilemma'.

Two important caveats are in order here. First, whether the anti-realist will be able to wield this argument will depend on the particular brand of anti-realism to which he subscribes. Recall, my argument's conclusion (3) proved problematic because scientific realists, qua realists, ought to believe evolutionary theory. But anti-realism arguably comes in degrees, and perhaps those espousing more moderate forms of anti-realism, which are only skeptical with respect to certain parts of our best scientific theories, may find themselves obliged to believe evolutionary theory as well. For example, Anjan Chakravartty's 'semi-realism' (2007, p. 47) distinguishes between the 'detection' and 'auxiliary' properties posited by the theories, accepting the former and rejecting the latter. Such a view may be close enough to 'full-blooded' scientific realism that its adherents are likewise compelled to believe evolutionary theory, in which case my argument, if sound, would also target it. The upshot of this is that anti-realists must be sufficiently thoroughgoing in order to deploy my argument against scientific realism, without it back-firing against their own position.

Secondly, there may be positions other than scientific anti-realism which may benefit from the 'Darwinian Dilemma'. For example, Arthur Fine's 'natural ontological attitude' (NOA 1986) affirms that our best scientific theories are 'true', but refrains from specifying the sense in which they are true (at least on one interpretation of it cf. Psillos 1999 pp. 229-232). This is meant to contrast with the view of scientific realists, who tell us that our best scientific theories are true in the sense that their content corresponds to mind-independent reality-as such, NOA is perhaps best conceived of as a quietist, rather than strictly anti-realist position (cf. Wolff 2019). Such quietism seems immune to my evolutionary sceptical challenge. ${ }^{17}$ Indeed, quietists need only believe propositions like 'water is $\mathrm{H} 2 \mathrm{O}$ ' and 'electrons have negative charge' without holding any further metaphysical beliefs about whether the objects to which these propositions refer constitute 'deep', 'real-world' mind-independent explanations of 'surface' observable phenomena. Thus, unlike scientific realists, they are not committed to the metaphysical belief that facts generally have explanations for their obtaining, and are therefore not a target of my main argument.

I conclude that quietists, along with (sufficiently thoroughgoing) anti-realists, can put forward my evolutionary sceptical challenge to scientific realism. Given the

\footnotetext{
17 Some have instead argued that Fine's 'natural ontological attitude' collapses to the realist position (e.g. Musgrave 1989). If this is true, my evolutionary sceptical challenge to realism could of course not form part of a case for this view.
} 
dominance of scientific realism in contemporary analytic philosophy (cf. Bourget and Chalmers 2013), this will be good news to critics desirous of turning the tide.

Acknowledgements I am grateful to my supervisor, Prof. Alexander Bird, for his comments and feedback. I would also like to thank the Arts and Humanities Research Council (AHRC) for funding my doctoral research.

Open Access This article is licensed under a Creative Commons Attribution 4.0 International License, which permits use, sharing, adaptation, distribution and reproduction in any medium or format, as long as you give appropriate credit to the original author(s) and the source, provide a link to the Creative Commons licence, and indicate if changes were made. The images or other third party material in this article are included in the article's Creative Commons licence, unless indicated otherwise in a credit line to the material. If material is not included in the article's Creative Commons licence and your intended use is not permitted by statutory regulation or exceeds the permitted use, you will need to obtain permission directly from the copyright holder. To view a copy of this licence, visit http://creativecommons.org/licen ses/by/4.0/.

\section{References}

Baker-Hytch, M. (2014). Religious diversity and epistemic luck. International Journal for Philosophy of Religion, 76(2), 171-191. https://doi.org/10.1007/s11153-014-9452-7.

Bogardus, T. (2016). Only all naturalists should worry about only one evolutionary debunking argument. Ethics, 126(3), 636-661. https://doi.org/10.1086/684711.

Boulter, S. (2007). The "evolutionary argument" and the metaphilosophy of commonsense. Biology and Philosophy, 22(3), 369-382. https://doi.org/10.1007/s10539-006-9032-z.

Bourget, D., \& Chalmers, D. (2013). What do philosophers believe? Philosophical Studies, 170(3), $465-500$.

Boyer, P. (2000). Natural epistemology or evolved metaphysics? Developmental evidence for early-developed, intuitive, category-specific, incomplete, and stubborn metaphysical presumptions. Philosophical Psychology, 13(3), 277-297. https://doi.org/10.1080/09515080050128123.

Campbell, D. (1960). Blind variation and selective retentions in creative thought as in other knowledge processes. Psychological Review, 67(6), 380-400. https://doi.org/10.1037/h0040373.

Chakravartty, A. (2007). A metaphysics for scientific realism: knowing the unobservable. Cambridge: Cambridge University Press.

Chang, H. (2008). Contingent transcendental arguments for metaphysical principles. Royal Institute of Philosophy Supplement, 63, 113-133. https://doi.org/10.1017/s1358246108000076.

Churchland, P. (1987). Epistemology in the age of neuroscience. Journal of Philosophy, 84(10), 544-553. https://doi.org/10.5840/jphil1987841026.

Churchland, P. (2009). Is evolutionary naturalism epistemologically self- defeating. Philo, 12(2), 135141. https://doi.org/10.5840/philo2009122.

Clark, A. (1984). Evolutionary epistemology and ontological realism. The Philosophical Quarterly, 34(137), 482. https://doi.org/10.2307/2219.

Clarke-Doane, J. (2016). Debunking and dispensability. In U. Leibowitz \& N. Sinclair (Eds.), Explanation ethics and mathematics: debunking and dispensability. Oxford: Oxford University Press.

Darwin, C., \& Darwin, F. (1888). The life and letters of Charles Darwin. London: John Murray.

De Cruz, H., \& De Smedt, J. (2006). The role of intuitive ontologies in scientific understanding-The case of human evolution. Biology and Philosophy, 22(3), 351-368. https://doi.org/10.1007/s1053 9-006-9036-8.

De Cruz, H., \& De Smedt, J. (2017). Intuitions and arguments: Cognitive foundations of argumentation in natural theology. European Journal for Philosophy of Religion, 9(2), 57. https://doi.org/10.24204 lejpr.v9i2.1934.

Dretske, F. (1988). Explaining behavior: Reasons in a world of causes. Cambridge: MIT Press.

Enoch, D. (2011). Taking morality seriously: A defense of robust realism. Oxford: Oxford University Press. 
Fine, A. (1986). Unnatural attitudes: Realist and instrumentalist attachments to science. Mind, 95(378), 149-179. https://doi.org/10.1093/mind/xcv.378.149.

Fine, K. (2001). The question of realism. Philosophers' Imprint, 1, 1-30.

Godfrey-Smith, P. (2003). Theory and reality: An introduction to the philosophy of science. Chicago: University of Chicago Press.

Graber, A., \& Golemon, L. (2019). Plantinga redux: Is the scientific realist committed to the rejection of naturalism? Sophia. https://doi.org/10.1007/s11841-018-0695-0.

Isserow, J. (2018). Evolutionary hypotheses and moral skepticism. Erkenntnis. https://doi.org/10.1007/ s10670-018-9993-8.

Keas, M. (2017). Systematizing the theoretical virtues. Synthese, 195(6), 2761-2793. https://doi. org/10.1007/s11229-017-1355-6.

Koperski, J. (2017). Theism, naturalism, and scientific realism. Epistemology and Philosophy of Science, 53(3), 152-166. https://doi.org/10.5840/eps201753354.

Lackey, J. (2008). What luck is not. Australasian Journal of Philosophy, 86(2), 255-267. https://doi. org/10.1080/00048400801886207.

Ladyman, J., \& Ross, D. (2007). Every thing must go: Metaphysics Naturalized. Oxford: Oxford University Press.

Lemos, J. (2002). Theism, evolutionary epistemology, and two theories of truth. Zygon®, 37(4), 789801. https://doi.org/10.1111/1467-9744.00458.

Lipton, P. (2003). Inference to the best explanation. London: Routledge.

Locke, D. (2014). Darwinian normative scepticism. In M. Bergmann \& P. Kain (Eds.), Challenges to moral and religious belief: Disagreement and evolution. Oxford: Oxford University Press.

McNabb, T. (2015). Defeating naturalism: Defending and reformulating Plantinga's EAAN. Eleutheria, 4(1), 4.

Mogensen, A. (2016). Do evolutionary debunking arguments rest on a mistake about evolutionary explanations? Philosophical Studies, 173(7), 1799-1817. https://doi.org/10.1007/s11098-015-0579-x.

Musgrave, A. (1989). Noa's Ark-fine for realism. The Philosophical Quarterly, 39(157), 383. https://doi. org/10.2307/2219825.

Nagel, T. (2012). Mind \& cosmos: Why the materialist neo-darwinian conception of nature is almost certainly false. Oxford University Press.

Plantinga, A. (1993). Warrant and proper function. New York: Oxford University Press.

Psillos, S. (1999). Scientific realism: How science tracks truth. Abingdon: Routledge.

Putnam, H. (1975). Mathematics, matter and method. Cambridge: Cambridge University Press.

Ruse, M. (1995). Evolutionary naturalism. London: Routledge.

Ruse, M. (1998). Taking Darwin seriously. Amherst. New York: Prometheus.

Severini, E., \& Sterpetti, F. (2017). Darwinism in metaethics: What if the universal acid cannot be contained? History and Philosophy of the Life Sciences. https://doi.org/10.1007/s40656-017-0154-1.

Sober, E. (2000). Philosophy of biology. Boulder: Westview Press.

Sober, E. (2015). Ockham's razors: a User's Manual. Cambridge: Cambridge University Press.

Stanford, K. (2006). Exceeding our Grasp: Science, history, and the problem of unconceived alternatives. Oxford: Oxford University Press.

Stewart-Williams, S. (2004). Darwin meets Socrates: Evolutionary psychology and the innate ideas debate. Ph.D. Massey University, Palmerston North, New Zealand.

Street, S. (2006). A Darwinian Dilemma for realist theories of value. Philosophical Studies, 127(1), 109166. https://doi.org/10.1007/s11098-005-1726-6.

Talbott, W. (2016). A new reliability defeater for evolutionary naturalism. Philosophy and Phenomenological Research, 93(3), 538-564. https://doi.org/10.1111/phpr.12338.

Trivers, R. (2011). The folly of fools. New York: Basic Books.

van Fraassen, B. (1989). Laws and symmetry. Oxford: Oxford University Press.

van Inwagen, Peter. (1997). Materialism and the psychological-continuity account of personal identity. Philosophical Perspectives, 11(s11), 305-319.

Vlerick, M., \& Broadbent, A. (2015). Evolution and epistemic justification. Dialectica, 69(2), 185-203.

White, R. (2010). You just believe that because. Philosophical Perspectives, 24(1), 573-615. https://doi. org/10.1111/j.1520-8583.2010.00204.x.

Wolff, J. (2019). Naturalistic quietism or scientific realism? Synthese, 196(2), 485-498.

Publisher's Note Springer Nature remains neutral with regard to jurisdictional claims in published maps and institutional affiliations. 